\title{
Molecular Characterization of Staphylococcus aureus Obtained from Blood Cultures of Paediatric Patients Treated in a Tertiary Care Hospital in Mexico
}

\author{
Guillermo Jose Vazquez- \\ Rosas $\mathbb{( D}^{1,2}$ \\ Jocelin Merida-Vieyra (iD) \\ Gerardo Aparicio-Ozores (iD ${ }^{2}$ \\ Antonino Lara-Hernandez ${ }^{3}$ \\ Agustin De Colsa (1) ${ }^{1,4}$ \\ Alejandra Aquino-Andrade (iD \\ 'Molecular Microbiology Laboratory, \\ Instituto Nacional de Pediatria, Mexico \\ City, Mexico; ${ }^{2}$ Medical Bacteriology \\ Laboratory, Instituto Politecnico \\ Nacional, Mexico City, Mexico; \\ ${ }^{3}$ Bacteriology Laboratory, Instituto \\ Nacional de Pediatria, Mexico City, \\ Mexico; ${ }^{4}$ Department of Paediatric \\ Infectious Diseases, Instituto Nacional de \\ Pediatria, Mexico City, Mexico
}

Purpose: Staphylococcus aureus is one of the main causative agents of hospital-acquired (HA) infections. In Mexico, information about the characteristics of clinical S. aureus isolates is limited. Our aim was to characterize $S$. aureus strains obtained from blood cultures of paediatric patients treated in a tertiary care hospital.

Materials and Methods: We analysed 249 S. aureus isolates over the period from 2006 to 2019, and their resistance profiles were determined. The isolates were classified into methicillin-resistant $S$. aureus (MRSA) or methicillin-sensitive $S$. aureus (MSSA). Staphylococcal cassettes chromosome mec (SCCmec) were detected. Virulence genes (cna, clfA, clfB, eta, $e t b$, fnbA, fnbB, hla, $p v l, s e c$, and tsst) were amplified, and their clonal relationships were established by pulsed-field gel electrophoresis (PFGE), multilocus sequence typing (MLST) and clonal complex (CC) typing. We reviewed one hundred medical files to collect clinical information.

Results: Thirty-eight percent of the isolates were MRSA and showed an expanded profile of resistance to other non-beta-lactam antibiotics, while MSSA strains presented a reduced resistance profile. SCCmec-II was the most frequent element (86.3\%). Eight virulence factors were detected in MSSA and six in MRSA. The $p v l$ gene was detected in four MRSA-SCC mec-IV isolates $(P \leq 0.0001)$. MRSA isolates were distributed among 14 clones and were classified into 15 sequence types (ST); the most frequent was ST1011 (17\%). The most common CC in MRSA was CC5 $(69 \%, P \leq 0.0001)$, and in MSSA, it was CC30 $(30 \%$, $P \leq 0.0001)$. Eighty-seven percent of MRSA isolates were HA-MRSA, and $13 \%$ were community-acquired MRSA (CA-MRSA). Of 21 HA-MRSA isolates, 17 had SCCmec-II, while two CA-MRSA isolates had SCCmec-IV. Of MSSA isolates, 77\% were derived from HA infections and $23 \%$ from CA infections.

Conclusion: MSSA isolates had more virulence factors. MRSA isolates were resistant to more non-beta-lactam antibiotics, and those with SCCmec-IV expressed a greater variety of virulence factors. Most $S$. aureus isolates belonged to CC5.

Keywords: MSSA, MRSA, virulence factors, clonal complex, SCCmec-II, CC5

\section{Introduction}

Among Gram-positive bacteria, Staphylococcus aureus is the main causative agent of hospital-acquired (HA) and community-acquired (CA) infections. S. aureus can cause mild skin and soft tissue infections and severe infections, including bacteraemia, sepsis, endocarditis, and osteomyelitis. ${ }^{1}$ One of the main challenges in the treatment of these infections is antibiotic resistance. Although the worldwide average prevalence of MRSA is $40 \%,{ }^{2}$ there are vast differences among different
Andrade

Molecular Microbiology Laboratory Instituto Nacional de Pediatria,

Insurgentes Sur 3700-C, Col. Insurgentes

Cuicuilco, Alcaldia Coyoacan, C.P. 04530,

Mexico City, Mexico

Tel +52 55 1084-0900 Ext. 1859

Email aaquinoa@pediatria.gob.mx 
geographical locations: in Latin America, the reported prevalence is between $6-80 \%{ }^{3}$ in Mexico, $52-57 \%{ }^{4}$ in China, 50\%; ${ }^{5}$ and in Europe, 0.9-26.8\%. ${ }^{6}$ Molecular characterization of $S$. aureus has become a tool for the investigation and detection of circulating and epidemic clones both in the hospital and in the community. These clones can be typed based on SCCmec, MLST, CC, PFGE and the presence of virulence factors, namely, Panton-Valentine leucocidin (PVL). ${ }^{7}$ HA infections are associated with MRSA clones with SCCmec elements I, II and IV of ST5 and $\mathrm{CC} 5{ }^{8}$

In Mexico, there is limited information about the molecular characteristics of MRSA associated with bacteraemia in paediatric patients. Some studies have analysed infections caused by $S$. aureus and comorbidities, such as cancer, and their clinical implications and have also classified the isolates based on their susceptibility profiles. ${ }^{9-11}$ In a tertiary care adult hospital, 444 linezolid (LZD)- and vancomycin (VAN)-sensitive MRSA isolates were studied; all had SCCmec-II. ${ }^{12}$ In a report from Latin America, 538 MRSA isolates were typed; 17 isolates from a single hospital in Mexico had SCCmec-II and were classified as USA100 and ST5. ${ }^{3}$ Our aim was to characterize 249 $S$. aureus isolates obtained from blood cultures of paediatric patients treated in a tertiary care hospital over a 14year period.

\section{Materials and Methods Study Setting}

Our study was conducted at the Instituto Nacional de Pediatria (INP), which is a tertiary care paediatric hospital with 235 beds, 40 subspecialties and 6981 discharges in 2017.

\section{Biological Material}

A total of 249 nonduplicate $S$. aureus isolates obtained from blood cultures of paediatric patients ( 0 to $<18$ yearold) with documented bacteraemia from 2006 to 2019 were analysed. The distribution of the isolates by year was as follows: $2006(n=24), 2007(n=24), 2008(n=24)$, $2009(\mathrm{n}=21), 2010 \quad(\mathrm{n}=23), 2011 \quad(\mathrm{n}=22), 2012 \quad(\mathrm{n}=15)$, $2013(\mathrm{n}=21), 2014 \quad(\mathrm{n}=15), 2015 \quad(\mathrm{n}=35), 2016 \quad(\mathrm{n}=21)$, $2018(\mathrm{n}=2)$, and $2019(\mathrm{n}=2)$. In 2017, we did not obtain any $S$. aureus isolates. We defined bacteraemia as positive peripheral blood cultures obtained from a patient with signs and symptoms of infection.

\section{Identification}

The isolates were identified using a BD Phoenix semiautomated microbiology system (Becton Dickinson, Franklin Lakes, New Jersey, USA). DNA extraction was performed with the QIAmp DNA mini ${ }^{\circledR}$ kit (Qiagen, Hilden, North Rhine-Westphalia, Germany). The DNA was eluted and stored at $-20{ }^{\circ} \mathrm{C}$ until use. Identification as $S$. aureus was corroborated by detection of the $n u c$ gene $^{13}$ and by amplification, sequencing, and analysis of the 16S rRNA gene. ${ }^{14-16}$ AmpliTaq Gold ${ }^{\circledR} 360$ Master Mix (Applied Biosystems $^{\mathrm{TM}}$, Foster City, California, USA) was used in all the reaction mixtures.

\section{Resistance Profile}

A disk diffusion test was performed for cefoxitin (FOX), gentamicin (GEN), ciprofloxacin (CIP), clindamycin (CLI), erythromycin (ERI), trimethoprim with sulfamethoxazole (SXT) and LZD using sensidiscs (Becton Dickinson, Franklin Lakes, Nueva Jersey, USA), and a broth microdilution test was performed for FOX (Sigma Aldrich, St. Louis, Missouri, USA) following the 2019 guidelines of the Clinical and Laboratory Standards Institute (CLSI) ${ }^{17}$

\section{Molecular Characterization of MRSA Isolates}

The presence of the femA and mecA genes was confirmed by PCR. ${ }^{18}$ Detection of the vanA gene was also performed. ${ }^{19}$ SCCmec elements were identified by multiplex PCR (mPCR). ${ }^{20}$ The presence of genes encoding virulence factors necessary for colonization ( $f n b A$, $f n b B$, clfA, clfB and cna), invasion ( $h l a$ and $p v l$ ), toxins ( $\mathrm{sec}$, eta and $e t b$ ), and superantigen (tsst) was detected. ${ }^{21-23}$ The GeneAmp ${ }^{\text {TM }}$ PCR System 9700 was used for all PCRs (Applied Biosystems ${ }^{\mathrm{TM}}$, Foster City, California, USA). We used S. aureus $\mathrm{ATCC}^{\circledR} 43300^{\mathrm{TM}}$ and Enterococcus faecium ATCC $^{\circledR} 29212^{\mathrm{TM}}$ as positive controls.

PFGE typing was performed using the CHEF Mapper XA System (Bio-Rad, Hercules, California, USA) following the guidelines established in the PulseNet protocol for MRSA from the Centers for Disease Control and Prevention. ${ }^{24}$ Analysis of clonal relationships was carried out using the Tenover criteria. ${ }^{25}$ A dendrogram was constructed using the program DendroUPGMA. ${ }^{26,27}$

ST detection was performed by MLST. $^{28}$ The sequences obtained were compared with those reported in the $S$. aureus MLST online database from the 
University of Oxford..$^{29,30}$ The six most widely distributed CCs were determined using $\mathrm{mPCR}{ }^{31}$

\section{Clinical Data}

We reviewed the medical files to collect clinical information, such as age, sex, comorbidity, primary infectious focus (PIF), clinical complications, outcome, length of hospital stay, and antibiotic treatment. An infection was considered HA if the date of the event of the site-specific infection criterion occurred on or after the 3rd calendar day of admission to an inpatient location where the day of admission was calendar day $1 .^{32}$ We categorized the age as follows: term neonatal (birth-27 days), infant (28 days-12 months), toddler (13 months -2 years of age), early childhood ( $2-5$ years of age), middle childhood (6-11 years of age), and early adolescence $(12-<18$ years of age $) .{ }^{33}$ To standardize the duration of treatment in all cases, the day of blood culture collection was taken as day zero.

\section{Statistical Analysis}

We compared the overall group infected with MRSA and those infected with MSSA. JPM 11 software (SAS Institute Inc., Cary, NC, USA) was used. The variables were described as frequencies and percentages. Categorical variables were compared using Pearson's $\chi^{2}$ test. A value of $P<0.05$ was considered statistically significant.

\section{Results}

\section{Detection of the nuc, I6S rRNA, femA, mecA and vanA Genes and Identification of the SCCmec Elements}

The nuc gene was amplified from 245 isolates, while the $16 \mathrm{~S}$ rRNA gene was sequenced from four isolates, confirming the 249 isolates as $S$. aureus. The femA gene was detected in $176(70.6 \%)$ isolates: 91 were MSSA and 85 were MRSA.

The vanA gene was not detected in any isolate. The $m e c A$ gene was amplified in 95 isolates (38.1\%), and these isolates were classified as MRSA. Three different SCCmec elements were found: SCCmec-I (3.1\%, n=3), SCCmec-II $(86.3 \%, \mathrm{n}=82)$, and SCCmec-IV $(9.4 \%, \mathrm{n}=9)$. In one isolate, it was not possible to determine the SCCmec element with the primers used in this study (Figure 1). Over the years, the MRSA isolates decreased in frequency, while the MSSA isolates increased (Figure 2).

\section{Susceptibility Profile}

The 95 MRSA isolates presented the following susceptibility profile: GEN $88.4 \%(\mathrm{n}=84)$, CIP $5.2 \%(\mathrm{n}=5)$, ERI $4.2 \%(\mathrm{n}=4)$, CLI 8.4\% $(\mathrm{n}=8)$, and SXT 92.6\% $(\mathrm{n}=88)$; all the isolates were sensitive to LZD. In the 154 isolates classified as MSSA, the following susceptibility profile was obtained: GEN 96\% ( $\mathrm{n}=148)$, CIP 89\% ( $\mathrm{n}=138)$, ERI 57\% ( $n=92)$, CLI 74\% ( $n=123)$, SXT 98\% $(n=152)$, and LZD $100 \%(\mathrm{n}=154)$. Twenty-two MSSA isolates with inducible resistance to CLI were detected (Table 1). ERI, CIP and CLI resistance was observed in the MRSA isolates $(P \leq 0.0001)$.

\section{Virulence Profile}

A gene that promotes colonization $(f n b A)$ and a gene that favours invasion $(h l a)$ were the most frequently observed virulence genes. Only four MRSA isolates had the $p v l$ gene in which SCCmec-IV was detected (Table 2). The clfA and $c l f B$ genes were not detected in any isolate. The $p v l$ gene was more frequent in the MRSA SCCmec-IV $(P \leq 0.0001)$.

\section{Determination of Clonality}

The 95 MRSA isolates were distributed among 14 clones by PFGE and were assigned letters A to $\mathrm{N} ; 50 \%$ of these isolates were grouped into clones $\mathrm{A} \mathrm{B}$ and $\mathrm{C}$ and contained SCCmec-II. Fifteen STs were determined to be distributed among all clones, the most frequent being ST1011 (17\%, $\mathrm{n}=4)$, ST5 $(13 \%, \mathrm{n}=3)$ and ST5529 $(13 \%, \mathrm{n}=3)$. MRSASCCmec-IV belonged to ST8, ST4335, ST544, ST1092, ST4732 and ST30, and the $p v l$ gene was amplified in only two ST4335 isolates. Among the total isolates, six CCs were detected, which were distributed as follows: $44.9 \%$ $(\mathrm{n}=112)$ CC5, 19.6\% ( $\mathrm{n}=49)$ CC30, 10.8\% $(\mathrm{n}=27) \mathrm{CC} 45$, $5.2 \%(\mathrm{n}=13) \mathrm{CC} 8,1.6 \%(\mathrm{n}=4) \mathrm{CC} 22$, and $0.8 \%(\mathrm{n}=2)$ CC1. CCs were not identified in $42(16.8 \%) S$. aureus isolates.

The MRSA isolates ( $\mathrm{n}=95)$ were grouped mainly into CC5 69.4\% ( $\mathrm{n}=66), \mathrm{CC} 8$ 8.4\% ( $\mathrm{n}=8), \mathrm{CC} 45$ 4.2\% $(\mathrm{n}=4)$, CC30 2.1\% ( $=2)$, and CC22 $1 \%(n=1)$; the type of CC was not classified in $14.7 \%(n=14)$ of the isolates (Figure 3). CC5 was statistically significant in the MRSA isolates $(P \leq 0.0001)$. The 154 MSSA isolates could not be classified into clones since they presented a great diversity of patterns obtained by PFGE, and the distribution of their CCs was different; $\mathrm{CC} 30$ was the most common with $30.5 \%(\mathrm{n}=47)$, followed by CC5 with $29.8 \%(\mathrm{n}=46)$, 
16

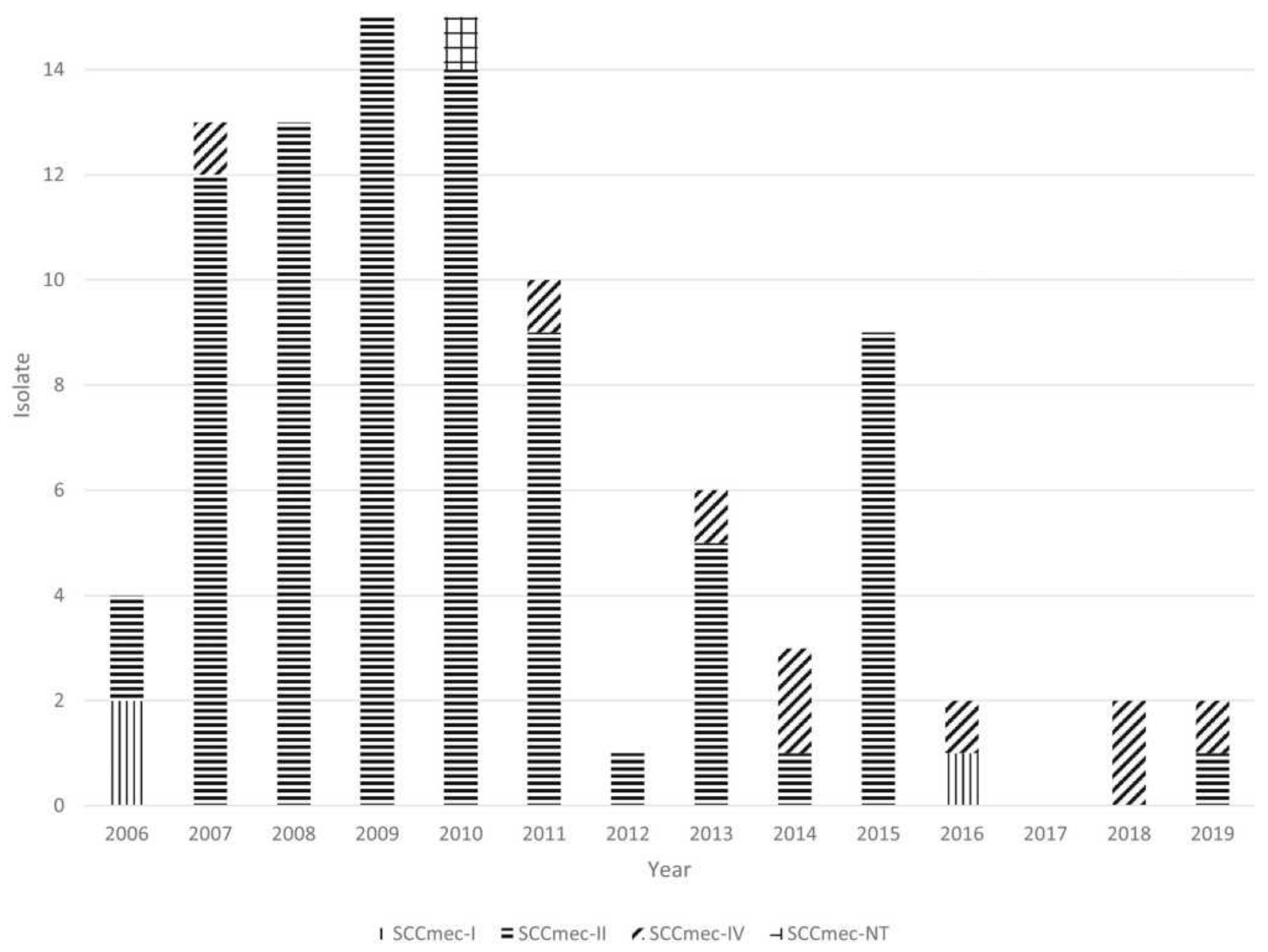

Figure I Distribution of SCCmec by year. A predominance of SCCmec-II was observed from 2006 to 2013 and in 2015. The first occurrence of SCCmec-IV was detected in 2007.

CC45 with $14.9 \%(n=23)$, CC8 with $3.2 \%(n=5)$, CC22 with $1.9 \%(n=3)$, and CC1 with $1.2 \%(n=2)$. CCs could not be identified in $18.1 \%(n=28)$ of the MSSA isolates. CC30 was statistically significant in the MSSA isolates $(P \leq 0.0001)$.

\section{Clinical Data}

Of the $249 S$. aureus isolates, clinical information was obtained for 100 of the patients from whom they were isolated. Twenty-four isolates were MRSA and 76 were MSSA. Seventy-nine percent of the patients with MRSA infections presented with comorbidities; among the most important of which were oncological diseases $(16 \%, n=4)$, nephropathies $(16 \%, n=4)$, and neuropathies $(16 \%, n=4)$. Central venous catheter (CVC) was identified as the main PIF $(66 \%, n=16)$. Eighty-seven percent $(n=21)$ of the infections were HA-MRSA, and $13 \%(n=3)$ were CAMRSA. Forty-five percent $(n=11)$ of the patients presented with complications derived from the infection and sepsis was the main complication, with $82 \%(n=9)$, followed by septic shock, with $18 \%(n=2)$. Twelve percent $(n=3)$ of the patients died, and two deaths were related to the infection. The definitive treatment for infections caused by MRSA was VAN $(79 \%, n=19)$, followed by teicoplanin (TEC) with $20 \%(n=5)$ (Table 3).

On the other hand, of the 76 patients with infections caused by MSSA, $81 \%(n=62)$ had a comorbidity, and the most frequent were oncological diseases, with $51 \%$ $(n=33)$. As in MRSA, a CVC was the main source of infection $(47 \%, n=36)$. Seventy-seven percent $(n=58)$ were HA-MSSA, and $23 \% \quad(n=18)$ were CA-MSSA. Thirty-eight percent $(n=27)$ of the patients presented with 


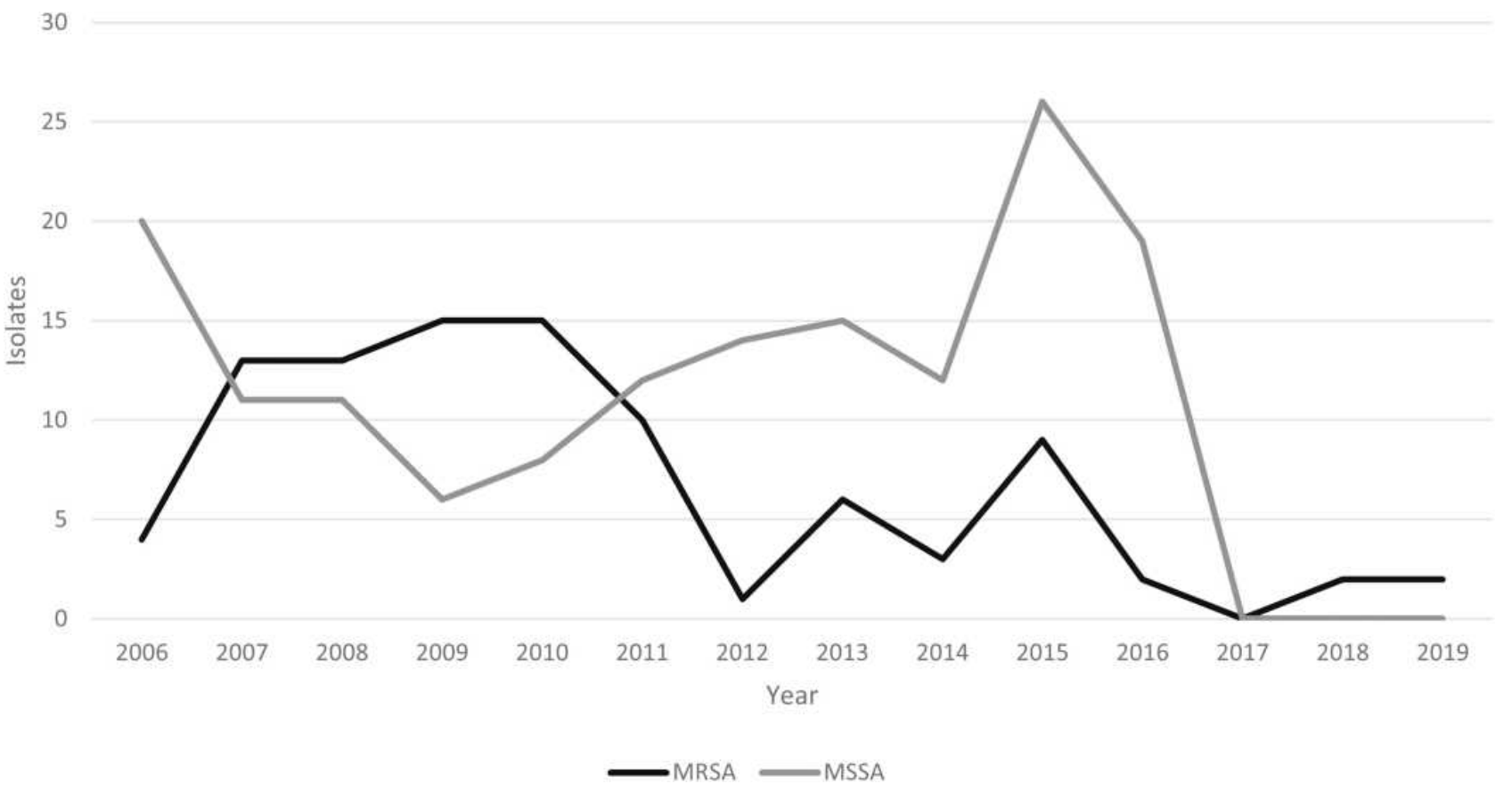

Figure 2 Frequency of MRSA and MSSA. A decrease in the frequency of MRSA can be observed since $201 \mathrm{I}$, while there was an increase in MSSA from $201 \mathrm{I}$ to 2016.

complications derived from the infection, and sepsis was the main complication, with $58 \%(\mathrm{n}=17)$, followed by septic shock, $20 \%(n=6)$. Thirteen percent $(n=10)$ of the patients died; two deaths were associated with the infection. The definitive treatment for infections caused by MSSA was dicloxacillin (DC) in $61 \%(\mathrm{n}=47)$, followed by VAN in $52 \%(n=40)$ and ceftriaxone (CRO) in $27 \%$ $(\mathrm{n}=21)$ (see Supplementary material).

\section{Discussion}

This study describes the main characteristics of a collection of $S$. aureus isolates obtained from blood cultures over 14 years in a tertiary care paediatric hospital in Mexico; $38.1 \%$ of these isolates were MRSA. The average frequency of MRSA worldwide is $40 \%,{ }^{2}$ but this frequency can vary among different regions. In the US, the frequencies of infections caused by MRSA range from $23.7-45 \%{ }^{34}$ in Europe, $0.9-26.8 \%{ }^{6,35}$ in Asia, $39.6-56.6 \% ;^{36}$ in Latin America, $6-80 \% ;^{3}$ and in Mexico, a frequency of $52-57 \%$ has been reported. ${ }^{4}$ A decrease in the frequency of MRSA worldwide from $45-40 \%$ has been observed, ${ }^{2}$ which may be due to different factors, for instance, the type of hospital, the origin of the isolates and the patient characteristics. In addition, this decrease may be related to the implementation of surveillance programmes that in some countries are very well structured, including the search and destroy policy of carriers in the Netherlands, the enhanced mandatory surveillance programme in the United Kingdom, and the nationwide MRSA Prevention Initiative in the U.S. ${ }^{37}$ However, there is not enough evidence to suggest that these programmes are solely responsible for this phenomenon. ${ }^{37-39}$ The common factor among the different studies is that control measures should always be accompanied by a programme for compliance with hand hygiene. ${ }^{40}$ Increases in the hospital frequency of MRSA could be related to the presence of outbreaks, such as the event that occurred in a cancer hospital in Mexico, where an increase in MRSA isolates from 4-20.4\% was observed in 2014 due to an outbreak, which was controlled by a programme that reinforced hand hygiene. ${ }^{9}$

In our study, a decrease in the frequency of MRSA was observed in recent years (2011-2019). It is important to mention that this could be the result of the implementation of a permanent monitoring programme for adequate handwashing in $2013 .{ }^{41}$ However, there is no surveillance and eradication programme for carriers of this pathogen.

The decrease in the frequency of MRSA and the increase in MSSA, as well as other Staphylococcus spp. that are causative agents of bacteraemia, has been associated with a greater diversity of virulence factors in these groups, favouring colonization and invasion. ${ }^{42,43}$ Our study focused on isolates from blood cultures of paediatric patients, and we observed a decrease in the presentation of 


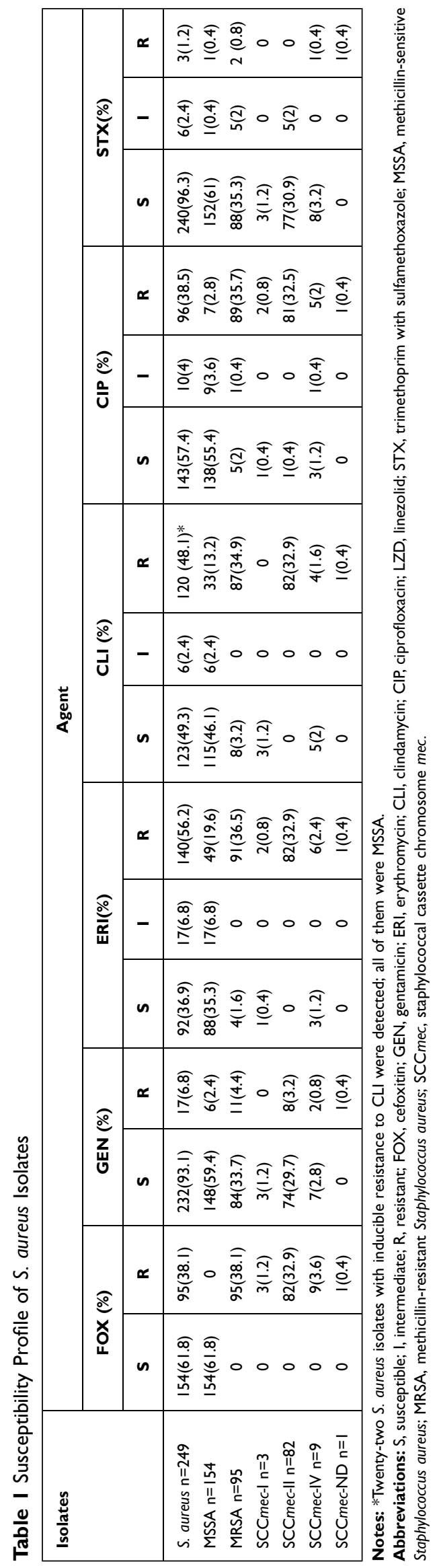

MRSA, similar to the global trend, so it is important to continue studying and monitoring this pathogen.

The treatment of choice for MRSA infections should focus on the susceptibility profile, age group, PIF and comorbidities. Although resistance to beta-lactams in S. aureus, which is mediated by mecA, limits some therapeutic options, it has been observed in different studies that there are still alternatives for the treatment of bacteraemia, such as LZD, daptomycin (DAP) and SXT. ${ }^{3,44}$ Our results also indicate that there is a high susceptibility to antibiotics, including oxazolidinones (LZD 100\%) folate inhibitors (SXT 96.3\%) and glycopeptides (VAN 100\%). In turn, MRSA remains susceptible to lincosamides, which are second-line treatments for MRSA, at levels close to $50 \%$ of susceptibility. ${ }^{45,46}$ Although VAN is the firstchoice antimicrobial for MRSA bacteraemia, ${ }^{46}$ there are other treatment alternatives, such as LZD, SXT and CLI, in monotherapy or in combination with DAP or ceftaroline (CPT) ${ }^{45-48}$ Therefore, interpretive reading of the antibiograms and the usage of first-choice antimicrobials are essential to reduce the risk of therapeutic failure and increase resistance rates.

The SCCmec elements allow to classify the MRSA strains into $\mathrm{HA}$ and $\mathrm{CA} .{ }^{49} \mathrm{~A}$ change was observed in the distribution of the SCCmec elements in our hospital. Type II decreased, while type IV was detected more frequently in recent years. In some regions of the world, there has been a decrease in cassettes I, II and III, historically associated with HA infections, and an increase in cassettes IV and V (associated with CA infections). This exchange has been widely described in the U.S., ${ }^{50} \operatorname{Iran}^{51}$ and South Africa. ${ }^{52}$

Currently, the detection of SCCmec elements and their classification is not sufficient to determine the best treatment, since the search for virulence factors is also important. In several studies, MRSA isolates have a greater variety of virulence genes, among which the presence of $p v l$, tsst and sea stand out, and these are mainly associated with MRSA isolates with SCCmec-IV. ${ }^{53-56}$

The frequency of $p v l$ in MRSA varies from 9-30\%; in Iran (9.7\%), South Africa (14\%), the US (26\%), and China $(30 \%) .{ }^{50-52,55}$ In the current study, we found the $p v l$ gene in four isolates (1.6\%), all with SCCmec-IV. In 2016, the first MRSA SCCmec-IV isolate with $p v l$ was detected. It is important to monitor the change in the distribution of SCCmec elements because in other countries, in particular the US, MRSA SCCmec-IV isolates reach $28 \%$, China $61 \%$, South Africa $48 \%$ and Japan $52.3 \% .{ }^{50-53,55}$ PVL is 
Table 2 Virulence Profile of S. aureus Isolates

\begin{tabular}{|c|c|c|c|c|c|c|c|c|c|}
\hline \multirow[t]{3}{*}{ Isolates } & \multicolumn{9}{|c|}{ Virulence Factors } \\
\hline & \multicolumn{3}{|c|}{ Colonization } & \multicolumn{2}{|c|}{ Invasion } & \multicolumn{3}{|c|}{ Toxins } & \multirow{2}{*}{$\begin{array}{c}\text { Superantigen } \\
\text { tsst (\%) }\end{array}$} \\
\hline & fnbA (\%) & fnbB (\%) & cna (\%) & hla (\%) & pvl (\%) & $\sec (\%)$ & eta (\%) & etb (\%) & \\
\hline S. aureus $n=249$ & 207(83.1) & $18(7.2)$ & $16(6.4)$ & $186(74.6)$ & $4(1.6)$ & $7(2.8)$ & $5(2)$ & $\mathrm{I}(0.4)$ & $38(15.2)$ \\
\hline MSSA $n=154$ & $135(54.2)$ & II (4.4) & $16(6.4)$ & $113(45.3)$ & 0 & $6(2.4)$ & $5(2)$ & $\mathrm{I}(0.4)$ & $37(14.8)$ \\
\hline MRSA $n=95$ & $72(28.9)$ & $7(2.8)$ & 0 & $73(29.3)$ & $4(1.6)$ & $\mathrm{I}(0.4)$ & 0 & 0 & $\mathrm{I}(0.4)$ \\
\hline SCCmec-I n=3 & $3(1.2)$ & $2(0.8)$ & 0 & $3(1.2)$ & 0 & 0 & 0 & 0 & 0 \\
\hline SCCmec-II n=82 & $63(25.3)$ & 0 & 0 & $64(25.7)$ & 0 & $\mathrm{I}(0.4)$ & 0 & 0 & 0 \\
\hline SCCmec-IV n=9 & $6(2.4)$ & $5(2)$ & 0 & $5(2)$ & $4(1.6)$ & 0 & 0 & 0 & $\mathrm{I}(0.4)$ \\
\hline SCCmec-ND n=I & 0 & 0 & 0 & $\mathrm{I}(0.4)$ & 0 & 0 & 0 & 0 & 0 \\
\hline
\end{tabular}

Notes: None of isolates harbored clfA and clfB.

Abbreviations: MSSA, methicillin-sensitive Staphylococcus aureus; MRSA, methicillin-resistant Staphylococcus aureus; SCCmec, staphylococcal cassette chromosome mec; ND, not determined.

one of the main virulence factors that complicate the clinical features and the therapeutic approach, since prolonged treatment of MRSA infections, producing this toxin, with VAN can lead to therapeutic failure, so it is necessary to use combinations, such as LZD and CLI, to inhibit the production of PVL. ${ }^{57,58}$

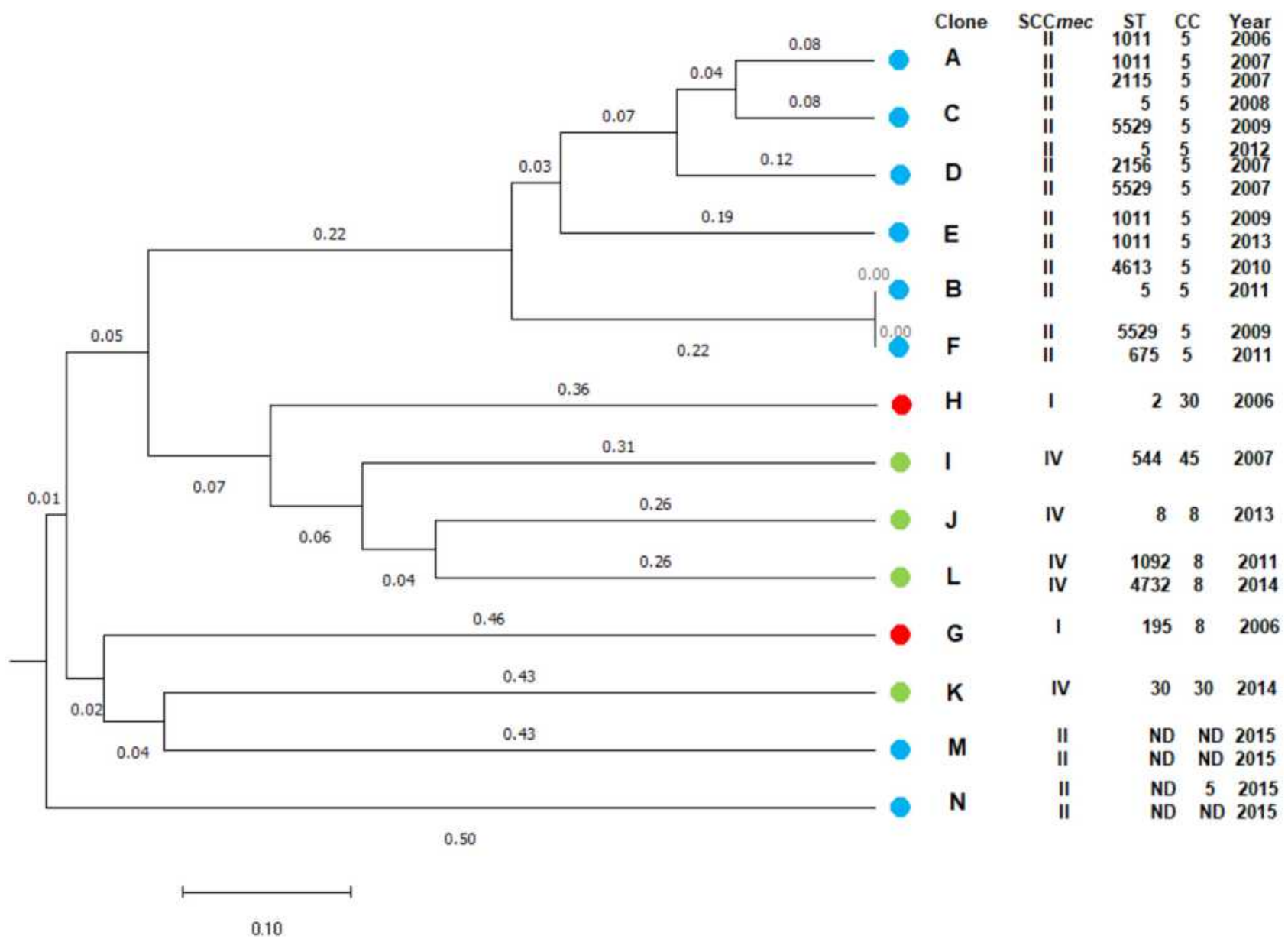

Figure 3 Characterization of the main S. aureus clones. SCCmec-II was found in eight of the 14 main clones, followed by SCCmec-IV in four of the I4 clones. Between 2016 and 2019, we obtained six MRSA isolates: two in 2016 (CC45 and CC8), two in 2018 (CC8 and ND) and two in 2019 (both CC45). None of these isolates clustered in a clone by PFGE.

Abbreviations: SCCmec, staphylococcal cassette chromosome mec; ST, sequence type; CC, clonal complex; ND, not determined. 


\begin{tabular}{|c|c|c|c|c|c|c|c|c|c|c|c|c|c|c|c|c|c|}
\hline \multirow{7}{*}{ 蒂 } & $\underset{m}{\stackrel{u}{F}}$ & $\begin{array}{l}\underset{+}{+} \\
\stackrel{0}{0} \\
0\end{array}$ & & & & & $\begin{array}{l}1 \\
+ \\
\$ \\
0\end{array}$ & & & 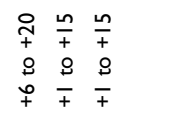 & & & & & & & \\
\hline & $\frac{z}{s}$ & \begin{tabular}{ll}
\multirow{4}{*}{} & \multirow{+}{+}{} \\
\multirow{+}{*}{} & 8 \\
0 & 0
\end{tabular} & 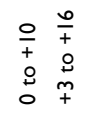 & $\begin{array}{l}\bar{q} \\
\dot{9} \\
0\end{array}$ & $\begin{array}{l}\stackrel{o}{+} \\
\stackrel{8}{q} \\
\stackrel{1}{1}\end{array}$ & $\begin{array}{l}\circ \\
\frac{0}{+} \\
8 \\
0\end{array}$ & $\begin{array}{l}\bar{q} \\
\stackrel{9}{+} \\
\stackrel{+}{+}\end{array}$ & $\begin{array}{l}\stackrel{m}{+} \\
\stackrel{+}{p} \\
m\end{array}$ & $\begin{array}{l}\circ \\
+ \\
\stackrel{9}{9} \\
m\end{array}$ & $\begin{array}{l}\frac{\nabla}{+} \\
\dot{8} \\
0\end{array}$ & \begin{tabular}{l}
\multirow{+}{*}{} \\
$\stackrel{9}{0}$ \\
0
\end{tabular} & $\begin{array}{l}\frac{m}{+} \\
\stackrel{g}{0} \\
0\end{array}$ & $\begin{array}{l}\stackrel{t}{+} \\
\dot{9} \\
\vdots \\
+\end{array}$ & $\begin{array}{l}\underset{+}{+} \\
\stackrel{9}{+} \\
\underset{+}{+}\end{array}$ & $\stackrel{8}{\underset{+}{+}}$ & $\begin{aligned} & \infty \\
&+ \\
& 0 \\
&+ \\
&+\end{aligned}$ & \\
\hline & Nิ & & & & & & & & & & & & & & & $\stackrel{\infty}{+}$ & \\
\hline & Ј & & & & & & $\begin{array}{l}\stackrel{\sim}{+} \\
\stackrel{9}{9} \\
\underset{+}{+}\end{array}$ & & & & & & $\begin{array}{l}\stackrel{n}{+} \\
\dot{0} \\
\dot{1}\end{array}$ & & $\stackrel{0}{\stackrel{0}{1}}$ & $\frac{8}{\mp} \frac{a}{+}$ & $\stackrel{8}{\underset{+}{+}}$ \\
\hline & $\stackrel{x}{v}$ & & & & & & & & & & & & & & $\begin{array}{l}\circ \\
+ \\
\stackrel{0}{+} \\
\stackrel{+}{+}\end{array}$ & & \\
\hline & $\stackrel{\circ}{\mathscr{E}}$ & & & & & & & & & & & $\begin{array}{l}\frac{m}{+} \\
\stackrel{g}{0} \\
0\end{array}$ & & $\begin{array}{l}\underset{\sim}{+} \\
\stackrel{q}{+} \\
\underset{+}{+}\end{array}$ & & $\begin{array}{l}q \\
+ \\
\dot{8} \\
0\end{array}$ & \\
\hline & U & & & & & & $\begin{array}{l}\bar{f} \\
\stackrel{8}{8} \\
0\end{array}$ & & & & & & & & $\mp$ & 。 & \\
\hline$\underline{n}$ & & $\underline{\underline{0}}$ 。요 & $\mathcal{\sim} \infty$ & $\overline{\underline{ }}$ & 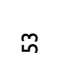 & q & $\alpha$ t & ก & $\bar{m}$ & $\hat{\sim} \hat{\sim} \hat{m}$ & 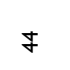 & $\stackrel{2}{\sim}$ & $\infty$ & $\underline{I}$ & $\stackrel{\infty}{\sim}$ & F & n \\
\hline 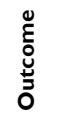 & & 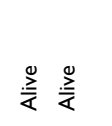 & 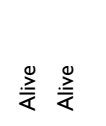 & $\stackrel{0}{\frac{2}{4}}$ & $\stackrel{0}{\frac{0}{4}}$ & 壱 & $\stackrel{0}{\stackrel{0}{*}}$ & 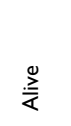 & $\stackrel{0}{\stackrel{2}{4}}$ & 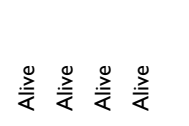 & 志 & $\stackrel{0}{\stackrel{2}{z}}$ & 点 & $\stackrel{0}{\frac{0}{4}}$ & $\stackrel{0}{\frac{2}{4}}$ & $\stackrel{0}{\frac{2}{4}}$ & $\stackrel{0}{\frac{0}{4}}$ \\
\hline 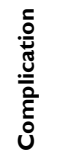 & & 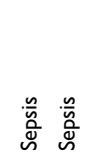 & 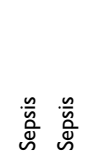 & $\stackrel{0}{\stackrel{0}{0}}$ & $\stackrel{0}{\stackrel{0}{2}}$ & $\begin{array}{l}\frac{n}{\bar{a}} \\
\stackrel{0}{\omega}\end{array}$ & 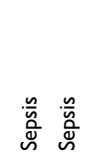 & 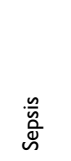 & 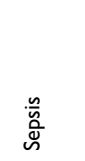 & 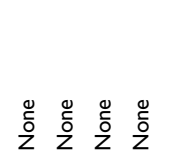 & $\begin{array}{l}\check{L} \\
\frac{\bar{o}}{\bar{n}} \\
\breve{\bar{a}} \\
\stackrel{\circ}{\circ}\end{array}$ & $\stackrel{0}{\frac{0}{2}}$ & $\stackrel{0}{\tilde{0}}$ & $\stackrel{0}{\frac{0}{0}}$ & $\stackrel{0}{\tilde{O}}$ & 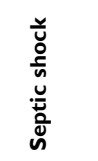 & $\begin{array}{l}\stackrel{0}{0} \\
\mathbf{z}\end{array}$ \\
\hline 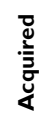 & & 㜽㜽 & 㜽至 & 㜽 & 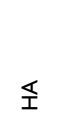 & $\overleftrightarrow{I}$ & 㜽至 & $\overleftrightarrow{I}$ & 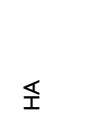 & 㜽㜽㜽㜽 & 㜽 & 㜽 & $\overleftrightarrow{I}$ & $\overleftrightarrow{I}$ & $₫$ & 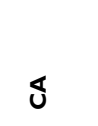 & 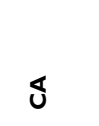 \\
\hline$\frac{\omega}{a}$ & & Ũ & 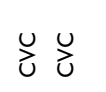 & u & u & u & U U & U & u & 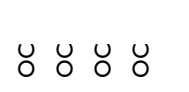 & 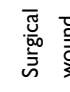 & $y$ & ¿ & u & ¿ & 总 & $\bar{\hbar}$ \\
\hline 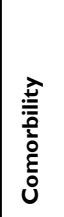 & & 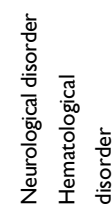 & 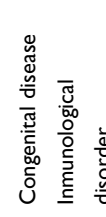 & 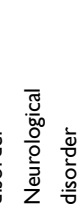 & 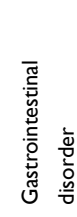 & 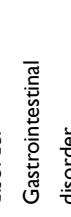 & 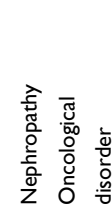 & 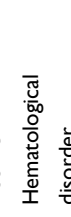 & 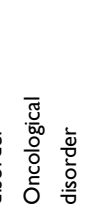 & 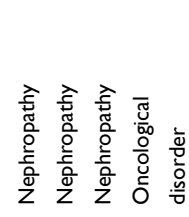 & $\frac{o}{\overline{0}}$ & 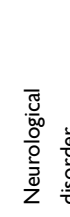 & 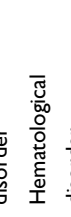 & 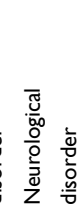 & 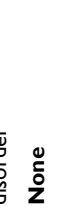 & 巳̊ & 巳̊̀ \\
\hline 苂 & & $==$ & $==$ & $=$ & $=$ & $=$ & $\geq=$ & $\geq$ & $=$ & $====$ & $=$ & $=$ & $=$ & $=$ & $\geq$ & $\geq$ & $\geq$ \\
\hline ্ֻঠ & & $\overline{\bar{i}} \overline{\bar{\alpha}}$ & $\stackrel{m}{\bar{\alpha}}$ & $\frac{m}{i}$ & $\frac{m}{i}$ & $\frac{m}{i}$ & $\frac{m}{i} \stackrel{m}{a}$ & $\frac{4}{a}$ & $\stackrel{4}{a}$ & $\stackrel{n}{i} \frac{n}{i} \stackrel{n}{i} \frac{n}{i}$ & $\stackrel{n}{a}$ & $\stackrel{n}{\bar{i}}$ & $\stackrel{n}{i}$ & $\stackrel{n}{i}$ & 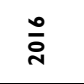 & $\stackrel{\infty}{i}$ & $\stackrel{\infty}{a}$ \\
\hline ڤ̊̀ & & $\Perp \Sigma$ & $\Sigma \Sigma$ & 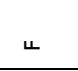 & $\Sigma$ & $\longleftarrow$ & $\Sigma \Sigma$ & $\Sigma$ & 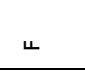 & ะ ะ ะ $\Sigma$ & $\Sigma$ & 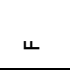 & $\Sigma$ & 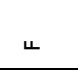 & $\longleftarrow$ & $\Sigma$ & $\Sigma$ \\
\hline 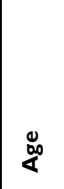 & & 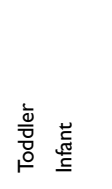 & 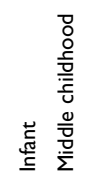 & 点 & 蒙 & 苾 & 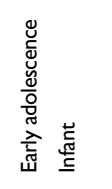 & 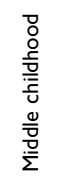 & 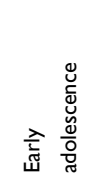 & 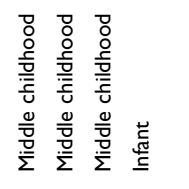 & 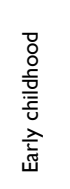 & 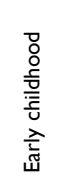 & 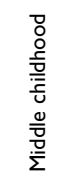 & $\begin{array}{l}\frac{\overline{\mathrm{w}}}{\overline{\mathrm{g}}} \\
\frac{\mathrm{o}}{\circ}\end{array}$ & 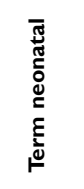 & 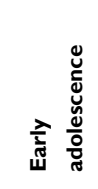 & 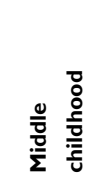 \\
\hline $\begin{array}{l}\frac{0}{0} \\
\frac{\pi}{0} \\
\underline{0}\end{array}$ & & 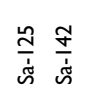 & 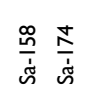 & $\frac{\hbar}{\dot{d}}$ & $\stackrel{\infty}{\stackrel{\infty}{\grave{d}}}$ & $\frac{\bar{\omega}}{\dot{\omega}}$ & $\begin{array}{ll}\frac{0}{\dot{\omega}} & \frac{\Omega}{\dot{\omega}} \\
\dot{\omega}\end{array}$ & $\frac{\hat{a}}{\dot{d}}$ & 胥 & 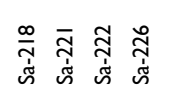 & $\begin{array}{l}\bar{J} \\
\stackrel{J}{N}\end{array}$ & 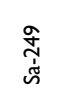 & 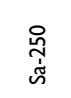 & $\begin{array}{l}\tilde{N} \\
\stackrel{N}{\sim}\end{array}$ & 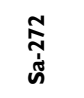 & $\begin{array}{l}\stackrel{2}{\pi} \\
\text { ஸn }\end{array}$ & $\underset{\substack{T \\
\tilde{D} \\
\tilde{n}}}{ }$ \\
\hline
\end{tabular}




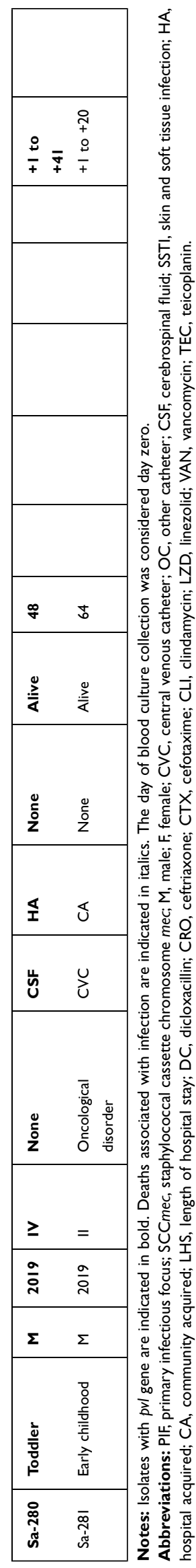

The MSSA isolates showed a greater diversity of virulence factor genes compared to MRSA, and it has been shown that MSSA, by presenting a greater number of virulence genes and acquiring resistance to antibiotics such as macrolides and lincosamides, complicates the clinical management of patients. ${ }^{59}$

The MRSA isolates with SCCmec-IV were more susceptible to antibiotics and several virulence genes were found, among which $p v l$, fnbA and $f n b B$ stand out. The SCCmec-II isolates mainly harboured invasion genes, such as hla and sec. It is important to determine the presence of virulence genes in isolates, regardless of whether they are MSSA or MRSA, since it allows for a better therapeutic approach and consideration of the possible clinical complications that the patient may experience, including fulminant pneumonia, endocarditis, or sepsis. ${ }^{57}$

The genetic characteristics of $S$. aureus have shown that each geographic region can have its own clonal distribution. ${ }^{60-62}$ This discrimination cannot be solely achieved with the PFGE method, and other tools such as MLST and CC typing are needed. According to several studies, CC5 is the main CC detected in the Americas and Asia. ${ }^{55,63-65}$ We observed the same trend, since of the 14 clones, $50 \%$ were grouped into CC 5 (69\%), followed by CC 8 (8.4\%). CC5 is more common in MRSA with SCCmec-II, and CC8 has been associated with MRSA-SCCmec-IV isolates with PVL, which leads to more serious clinical conditions, in particular fulminant pneumonia or deep vein thrombosis. ${ }^{58}$ In our study, $14.7 \%$ of the MRSA and $18 \%$ of the MSSA isolates could not be grouped into any CC because the method used only detected the six most common CCs distributed around the world. ${ }^{31}$ PFGE, MLST, CC, spa typing, SCCmec, $\mathrm{CC}$, and virulence factor detection are methods used to determine the MRSA epidemiology, and this information can impact the treatments applied to patients. ST5 was one of the most common in our collection, which coincides with that reported in other Latin American countries, such as Brazil (89\%) and Guatemala (95\%), but differs from that reported in Colombia (79\%) and Ecuador (72\%), where ST8 occurs more frequently. ${ }^{3}$

To control the dispersion of MRSA in our hospital, we must implement a permanent surveillance programme to study its spread and continue to monitor the different genetic characteristics of MRSA.

\section{Conclusion}

The MRSA isolates were grouped into clones, while the MSSA did not have a clonal relationship; however, most 
of the S. aureus isolates belonged to $\mathrm{CC} 5$, and the interpretation of the susceptibility profiles of the isolates showed that there are still first-line therapeutic options for the management of $S$. aureus infections in our hospital to control and prevent the emergence of new resistance strains.

MRSA was detected in $38.1 \%$ of the isolates from our hospital. The frequency of MRSA decreased over the years, while an increase in the number of MSSA was observed. SCCmec-II was the most common among the studied isolates; however, starting in 2016, the frequency of SCCmec-IV increased.

MRSA strains containing SCCmec-IV exhibited a greater variety of virulence genes related to colonization or invasion than those containing SCCmec-II. However, the $p v l$ gene was only detected in $1.6 \%$ of the isolates.

\section{Abbreviations}

CA, Community-acquired; CA-MRSA, Communityacquired methicillin-resistant Staphylococcus aureus; CC, Clonal complex; CIP, Ciprofloxacin; CLI, Clindamycin; CLSI, Clinical and Laboratory Standards institute; CPT, Ceftaroline; CRO, Ceftriaxone; CVC, Central venous catheter; DAP, Daptomycin; DC, Dicloxacillin; ERI, Erythromycin; FOX, Cefoxitin; GEN, Gentamicin; HA, Hospital-acquired; HA-MRSA, Hospital-acquired methicillin-resistant Staphylococcus aureus; INP, Instituto Nacional de Pediatria; LHS, Length of hospital stay; LZD, Linezolid; MLST, Multilocus sequence typing; mPCR, Multiplex PCR; MRSA, Methicillin-resistant Staphylococcus aureus; MSSA, Methicillin-sensitive Staphylococcus aureus; PIF, Primary infectious focus; PFGE, Pulsed-field gel electrophoresis; PVL, PantonValentine leucocidin; SCCmec, Staphylococcal cassette chromosome mec; ST, Sequence type; SXT, Trimethoprim with sulfamethoxazole; TEC, Teicoplanin; VAN, Vancomycin.

\section{Data Sharing Statement}

We confirm the data patient were deidentified. All the data generated or analysed during this study are included in this published article.

\section{Ethics Approval and Informed Consent}

This study was approved by the research, ethics, and biosafety committees of Instituto Nacional de Pediatria
(IRB: 00008064 and IRB: 00008065) under registration INP 2018/17. The ethics committee did not require informed consent because the samples obtained were part of the standard care for hospitalized patients, and the isolates were obtained retrospectively. The patient data were deidentified.

\section{Author Contributions}

All authors contributed to data analysis, drafting or revising the article, have agreed on the journal to which the article will be submitted, gave final approval of the version to be published, and agree to be accountable for all aspects of the work.

\section{Funding}

This study was supported by the National Council of Science and Technology (Consejo Nacional de Ciencia y Tecnología-CONACYT) through project FOSSIS2017-1-289537; by the Instituto Politecnico Nacional through SIP 20202136 and by modality A funding resources INP-2019 and INP-2020 under registration INP-2018/017.

\section{Disclosure}

The authors declare that they have no competing interests.

\section{References}

1. Turner NA, Sharma-Kuinkel BK, Maskarinec SA, et al. Methicillinresistant Staphylococcus aureus: an overview of basic and clinical research. Nat Rev Microbiol. 2019;17(4):203-2018. doi:10.1038/ s41579-018-0147-4

2. Diekema DJ, Pfaller MA, Shortridge D, Zervos M, Jones RN. Twentyyear trends in antimicrobial susceptibilities among Staphylococcus aureus from the SENTRY antimicrobial surveillance program. Open Forum Infect Dis. 2019;6:S47-S53. doi:10.1093/ofid/ofy270

3. Arias CA, Reyes J, Carvajal LP, et al. A prospective cohort multicenter study of molecular epidemiology and phylogenomics of Staphylococcus aureus bacteremia in nine Latin American countries. Antimicrob Agents Chemother. 2017;61(10):e00816-17. doi:10.1128/ AAC.00816-17

4. Seas C, Garcia C, Salles MJ, et al. Staphylococcus aureus bloodstream infections in Latin America: results of a multinational prospective cohort study. J Antimicrob Chemother. 2019;73:212-222. doi:10. 1093/jac/dkx350

5. Dai Y, Liu J, Guo W, et al. Decreasing methicillin-resistance Staphylococcus aureus (MRSA) infections is attributable to the disappearance of predominant MRSA ST239 clones, Shangai, 2008-2017. Emerg Microbes Infect. 2019;8:471-478. doi:10.1080/22221751.20 19.1595161

6. Hassoun A, Linden PK, Friedman B. Incidence, prevalence and management of MRSA bacteremia across patient populations- a review of recent developments in MRSA management and treatment. Crit Care. 2017;21:211. doi:10.1186/s13054-017-1801-3

7. Li X, Huang T, Xu K, Li C, Li Y. Molecular characteristics and virulence gene profiles of Staphylococcus aureus isolates in Hainan, China. BMC Infect Dis. 2019;19:873. doi:10.1186/s12879-019-4547-5 
8. Challagundla L, Reyes J, Rafiqullah I, et al. Phylogenomic classification and the evolution of clonal complex 5 methicillin-resistant Staphylococcus aureus in the western hemisphere. Front Microbiol. 2018;9:1901. doi:10.3389/fmicb.2018.01901

9. Velázquez-Acosta C, Cornejo-Juárez $\mathrm{P}$, Volkow-Fernández $\mathrm{P}$. Multidrug resistance E-ESKAPE strains isolated from blood cultures in patients with cancer. Salud Publica Mex. 2018;60:151-157. doi: $10.21149 / 8767$

10. Chacon-Cruz E, Rivas-Landeros RM, Volker-Soberanes ML, Lopatynsky-Reyes EZ, Becka C, Alvelais-Palacios JA. 12 years active surveillance for pediatric pleural empiema in a mexican hospital: effectiveness of pneumococcal 13-valent conjugate vaccine; and early emergence of methicillin-resistant Staphylococus aureus. Ther Adv Infect Dis. 2019;6:2049936119839312.

11. Garza-García E, Morfín-Otero R, Mendoza-Olazarán S, et al. A Snapshot of antimicrobial resistance in Mexico. Results from 47 centers from 20 states during a six-month period. PLoS One. 2019;14:e0209865. doi:10.1371/journal.pone.0209865

12. Ponce-de-león A, Camacho-Ortiz A, Macías AE, et al. Epidemiology and clinical characteristics of Staphylococcus aureus bloodstream infections in a tertiary-care center in Mexico City: 2003-2007. Rev Invest Clin. 2010;62:553-559.

13. Brakstad OG, Aasbakk K, Maeland JA. Detection of Staphylococcus aureus by polymerase chain reaction amplification of the nuc gene. J Clin Microbiol. 1992;30:1654-1660. doi:10.1128/JCM.30.7.16541660.1992

14. Relman DA. Universal bacterial $16 \mathrm{~S}$ rDNA amplification and sequencing. In: Persing DH, Smith TF, Tenover FC, White TT, editors. Diagnostic Molecular Microbiology: Principles and Applications. Washington; D.C: American Society of Microbiology; 1993:489-495.

15. Morgulis A, Coulouris G, Raytselis Y, Madden TL, Agarwala R, Schäffer AA. Database Indexing for Production MegaBLAST Searches. Bioinrmatics. 2008;24:1757-1764. doi:10.1093/bioinformatics/btn 322

16. Zhang Z, Schwartz S, Wagner L, Miller W. A greedy algorithm for aligning DNA sequences. J Comput Biol. 2000;7(1-2):203-214. doi:10.1089/10665270050081478

17. CLSI. Performance Standard for Antimicrobial Susceptibility Testing 30th. CLSI supplement M100. Wayne; PA: Clinical and Laboratory Standards Institute; 2019

18. Louie L, Goodfellow J, Mathieu P, Glatt A, Louis M, Simor AE. Rapid detection of methicillin-resistant staphylococci from blood culture bottles by using a multiplex PCR assay. J Clin Microbiol. 2002;40:2786-2790. doi:10.1128/JCM.40.8.2786-2790.2002

19. Miele A, Bandera M, Goldstein BP. Use of primers selective for vancomycin resistance genes to determine van genotype in enterococci and to study gene organization in VanA isolates. Antimicrob Agents Chemother. 1995;39(8):1772-1778. doi:10.1128/AAC.39.8. 1772

20. Boye K, Bartels MD, Andersen IS, Meller JA, Westh H. A new multiplex PCR for easy screening of methicillin-resistant Staphylococcus aureus SCCmec types I-V. Clin Microbiol Infect. 2007;13:725-727. doi:10.1111/j.1469-0691.2007.01720.x

21. Lina G, Piémont Y, Godail-Gamot F, et al. Involvement of Panton-Valentine leukocidin producing Staphylococcus aureus in primary skin infections and pneumonia. Clin Infect Dis. 1999;29: 1128-1132. doi:10.1086/313461

22. Azimian A, Fazeli H, Naderi M. et al. Genetic characterization of a vancomycin-resistant Staphylococcus aureus isolate form the respiratory tract of a patient in a university hospital in northeaster Iran. J Clin Microbiol;2012. 3581-3585. doi:10.1128/JCM.01727-12

23. Eftekhar F, Rezaee R, Azad M, Azimi H, Goudarzi H, Goudarzi M. Distribution of adhesion and toxin genes in Staphylococcus aureus strains recovered from hospitalized patients admitted to the UCI. Arch Pediatr Infect Dis. 2017;5:e39349.
24. CDC. Oxacillin Resistant Staphylococcus Aureus on PulseNet $(O P N)$ : Laboratory Protocol for Molecular Typing of S. Aureus by Pulsed Field Gel Electrophoresis. Atlanta: National Center for Diseases; 2002.

25. Tenover FC, Arbeit RD, Goering RV, et al. Interpreting chromosomal DNA restriction patterns produced by pulsed-field gel electrophoresis: criteria for bacterial strain typing. $J$ Clin Microbiol. 1995;33:2233-2239. doi:10.1128/JCM.33.9.2233-2239.1995

26. Garcia-Vallve S, Palau J, Romeu A. DendroUPGMA: a dendrogram construction utility. Available from: http://usuaris.tinet.cat/debb/ UPGMA. Accessed September 20, 2019.

27. Garcia-Vallve S, Palau J, Romeu A. Horizontal gene transfer in glycosyl hydrolases inferred from codon usage in Escherichia coli and Bacillus subtilis. Mol Biol Evol. 1999;16(9):1125-1134. doi:10.1093/oxfordjournals.molbev.a026203

28. Enright MC, Day NPJ, Davies CE, Peacock SJ, Spratt BG. Multilocus sequence typing for characterization of methicillin-resistant and methicillin-susceptible clones of Staphylococcus aureus. J Clin Microbiol. 2000;38:1008-1015. doi:10.1128/JCM.38.3.1008-1015.2000

29. PubMLST. Available from: https://pubmlst.org. Accessed November $15 ; 2019$.

30. Jolley KA, Bray JE, Maiden MC. Open-access bacterial population genomics: bIGSdb software, the PubMLST.org website and their applications. Wellcome Open Res. 2018;3:124. doi:10.12688/ wellcomeopenres.14826.1

31. Cockfield JD, Pathak S, Edgeworth JD, Lindsay JA. Rapid determination of hospital-acquired methicillin-resistant Staphylococcus aureus lineages. J Med Microbiol. 2007;56:614-619. doi:10.1099/ jmm.0.47074-0

32. National Healthcare Safety Network. Identifying healthcare-associated infections (HAI) for NHSN surveillance. 2021. Available from: https:// www.cdc.gov/nhsn/PDFs/pscManual/2PSC_IdentifyingHAIs NHSNcurrent.pdf. Accessed February 15, 2021.

33. Williams K, Thomson D, Seto I, et al. Standard 6: age groups for pediatric trials. Pediatrics. 2012;3:153-160. doi:10.1542/peds.2012$0055 \mathrm{I}$

34. Duncan LR, Smith CJ, Flamm RK, Mendes RE. Regional analysis of telavancin and comparator antimicrobial activity against multidrugresistant Staphylococcus aureus collected in the USA 2014-2016. J Glob Antimicrob Resist. 2020;20:118-123. doi:10.1016/j.jgar.20 19.07.007

35. Mendes RE, Sader HE, Castanheira M, Flamm RK. Distribution of main Gram-positive pathogens causing bloodstream infections in United States and European hospitals during the SENTRY antimicrobial surveillance program (2010-2016): concomitant analysis of oritavancin in vitro activity. $J$ Chemother. 2018;30:280-289. doi:10.1080/1120009X.2018.1516272

36. Carvalhaes CG, Huband MD, Reinhart HH, Flamm RK, Sader HS. Antimicrobial activity of omadacycline tested against clinical bacterial isolates from hospitals in maingland China, Hon Kong, and Taiwan: results from the SENTRY antimicrobial surveillance program (2013 to 2016). Antimicrob Agents Chemother. 2019;63: e02262-18. doi:10.1128/AAC.02262-18

37. Rubin MA, Samore MH, Harris AD. The importance of contact precautions for endemic methicillin-resistant Staphylococcus aureus and vancomycin-resistant enterococci. JAMA. 2017;319:863-864. doi:10.1001/jama.2017.21122

38. Rolain JM, Abat C, Brouqui P, Raoult D. Worldwide decrease in methicillin-resistant Staphylococcus aureus: do we understand something? Clin Microbiol Infect. 2015;21:515-517. doi:10.1016/j. cmi.2015.04.017

39. Marra AR, Edmond MB, Schweizer ML, Ryan GW, Diekema DJ. Discontinuing contact precautions for multidrug-resistant organisms: a systematic literature review and meta-analysis. Am J Infect Control. 2018;46(3):333-340. doi:10.1016/j.ajic.2017.08.031 
40. Fätkenheuer G, Hirschel B, Harbarth S. Screening and isolation to control meticillin-resistant Staphylococcus aureus: sense, nonsense, and evidence. Lancet. 2015;385(9973):1146-1149. doi:10.1016/ S0140-6736(14)60660-7

41. Hernandez HG, Guimera D, Rosas A, et al. One-to-one training to increase correct technique in hand hygiene practice. Am J Infect Control. 2013;41:S14-S15. doi:10.1016/j.ajic.2013.03.027

42. Argemi X, Hansmann Y, Prola K, Prévost G. Coagulase-negative staphylococci pathogenomics. Int J Mol Sci. 2019;20(5):E1215. doi:10.3390/ijms20051215

43. Becker K, Both A, Weibelberg S, Heilmann C, Rohde H. Emergence of coagulase-negative staphylococci. Expert Rev Anti Infect Ther. 2020;2:1-18.

44. Pfaller MA, Sader HS, Flamm RK, Castanheira M, Smart JI, Mendes RE. In vitro activity of telavancin against clinically important Gram-positive pathogens from 69 U.S. medical centers (2025): potency analysis by U.S. census divisions. Microb Drug Resist. 2017;23:718-726. doi:10.1089/mdr.2017.0022

45. Eliakim-Raz N, Hellerman M, Yahav D, et al. Trimetrophim/sulfamethoxazole versus vancomycin in the treatment of healthcare/ventilator-associated MRSA pneumonia: a case-control study. J Antimicrob Chemother. 2017;72:882-887. doi:10.1093/jac/dkw510

46. Tissot-Dupont H, Gouriet F, Oliver L, et al. High-dose trimethoprim-sulfamethoxazole and clindamycin for Staphylococcus aureus endocarditis. Int J Antimicrob Agents. 2019;54(2):143-148. doi:10.1016/j.ijantimicag.2019.06.006

47. Paul M, Bishara J, Yahav D, et al. Trimethoprim-sulfamethoxazole versus vancomycin for severe infections caused by methicillin resistant Staphylococcus aureus: randomized controlled trial. BMJ. 2015;350:h2219. doi:10.1136/bmj.h2219

48. Lewis PO, Heil EL, Covert KL, Cluck DB. Treatment strategies for persistent methicillin-resistant Staphylococcus aureus bacteraemia. J Clin Pharm Ther. 2018;43(5):614-625. doi:10.1111/jcpt.12743

49. Naorem RS, Urban P, Goswami G, Fekete C. Characterization of methicillin-resistant Staphylococcus aureus through genomics approach. Biotech. 2020;10(9):401. doi:10.1007/s13205-020-023 $87-\mathrm{y}$

50. Nelson MU, Bizzarro MJ, Baltimore RS, Dembry LM, Gallagher PG. Clinical and molecular epidemiology of methicillin-resistant Staphylococcus aureus in a neonatal intensive care unit in the decade following implementation of an active detection and isolation program. J Clin Microbiol. 2015;53:2492-2501. doi:10.1128/ JCM.00470-15

51. Tajik S, Najar-Peerayeh S, Bakhshi B, Gomohammadi R. Molecular characterization of community-associated methicillin-resistant Staphylococcus aureus in Iranian burn patients. Iran J Pathol. 2019;14:284-289. doi:10.30699/IJP.2019.94189.1917

52. Singh-Moodley A, Strasheim W, Mogokotleng R, Ismail H, Perovic O. Unconventional SCCmec types and low prevalence of the Panton-Valentine Leukocidin exotoxin in South African blood culture Staphylococcus aureus surveillance isolates, 2013-2016. PLoS One. 2019;14:e0225726. doi:10.1371/journal. pone. 0225726
53. Mitsumoto-Kaseida F, Murata M, Toyoda K, et al. Clinical and pathogenic features of SCCmec type II and IV methicillin-resistant Staphylococcus aureus in Japan. J Infect Chemother. 2017;23 (2):90-95. doi:10.1016/j.jiac.2016.11.001

54. Samadi R, Ghalvazand Z, Mirnejad R, Nikmanesh B, Eslami G. Antimicrobial resistance and molecular characteristics of methicillin-resistant Staphylococcus aureus isolates from children patients in Iran. Infect Drug Resist. 2019;12:3849-3857. doi:10.2147/IDR.S229394

55. Wang X, Shen Y, Huang W, Zhou Y. Characterisation of communityacquired Staphylococcus aureus causing skin and soft tissue infections in a children's hospital in Shanghai, China. Epidemiol Infect. 2019;147:e323. doi:10.1017/S0950268819002127

56. Kateete DP, Asiimwe BB, Mayanja R, et al. Nasopharyngeal carriage, spa types and antibiotic susceptibility profiles of Staphylococcus aureus from healthy children less than 5 years in Eastern Uganda. BMC Infect Dis. 2019;19:1023. doi:10.1186/s12879-019-4652-5

57. Hodille E, Rose W, Diep BA, Goutelle S, Lina G, Dumitrescu O. The role of antibiotics in modulating virulence in Staphylococcus aureus. Clin Microbiol Rev. 2017;30:887-917. doi:10.1128/CMR.00120-16

58. Hoppe PA, Holzhauer S, Lala B, et al. Severe infections of Panton-Valentine leukocidin positive Staphylococcus aureus in children. Medicine. 2019;98:e17185. doi:10.1097/MD.0000000000017185

59. Imani-Fooladi AA, Ashrafi E, Tazandareh SG, et al. The distribution of pathogenic and toxigenic genes among MRSA and MSSA clinical isolates. Microb Pathog. 2015;81:60-66. doi:10.1016/j.micpath.20 15.03.013

60. Perovic O, Iyaloo S, Kularatne R, et al. Prevalence and trends of Staphylococcus aureus bacteraemia in hospitalized patients in South Africa, 2010 to 2012: laboratory-based surveillance mapping of antimicrobial resistance and molecular epidemiology. PLoS One. 2015;10:e0145429. doi:10.1371/journal.pone.0145429

61. de Oliveira CF, Morey AT, Santos JP, et al. Molecular and phenotypic characteristics of methicillin-resistant Staphylococcus aureus isolated from hospitalized patients. J Infect Dev Ctries. 2015;9:743-751. doi: $10.3855 /$ jidc. 5868

62. Tekeli A, Ocal DN, Ozmen BB, Karahan ZC, Dolapci I. Molecular characterization of methicillin-resistant Staphylococcus aureus bloodstream isolates in a Turkish University Hospital between 2002 and 2012. Microb Drug Resist. 2016;22:564-569. doi:10.1089/mdr.2015.0116

63. Kang GS, Jung YH, Kim HS, et al. Prevalence of major methicillin-resistant Staphylococcus aureus clones in Korea between 2001 and 2008. Ann Lab Med. 2016;36:536-541. doi:10.3343/ alm.2016.36.6.536

64. Udo EE, Al-Sweih N. Dominance of community-associated methicillin-resistant Staphylococcus aureus clones in a maternity hospital. PLoS One. 2017;12:e179563. doi:10.1371/journal.pone. 0179563

65. Alfouzan W, Udo EE, Modhaffer A, Alosaimi A. Molecular characterization of methicillin-resistant Staphylococcus aureus in a tertiary care hospital in Kuwait. Sci Rep. 2019;9:18527. doi:10.1038/s41598019-54794-8
Infection and Drug Resistance

\section{Publish your work in this journal}

Infection and Drug Resistance is an international, peer-reviewed openaccess journal that focuses on the optimal treatment of infection (bacterial, fungal and viral) and the development and institution of preventive strategies to minimize the development and spread of resistance. The journal is specifically concerned with the epidemiology of antibiotic resistance and the mechanisms of resistance development and diffusion in both hospitals and the community. The manuscript management system is completely online and includes a very quick and fair peerreview system, which is all easy to use. Visit http://www.dovepress.com/ testimonials.php to read real quotes from published authors. 